$\begin{array}{ll} & \text { Ecc } \\ & \text { Esta obra está sob o direito de } \\ & \text { Licença Creative Commons } \\ \text { Atribuição 4.0 Internacional. }\end{array}$

\title{
LETRAMENTO E ALFABETIZAÇÃO: OS ESTUDOS ORIGINAIS NO BRASIL
}

\author{
Elaine da Silva Santos ${ }^{1}$ \\ Betijane Soares de Barros ${ }^{2}$ \\ Maria Edleuza da Paz \\ Alessandra Porfírio da Silva ${ }^{4}$ \\ Celsa dos Santos Albuquerque ${ }^{5}$ \\ Léa Karla Carvalho P. Barros ${ }^{6}$ \\ Joselito Araújo Silva ${ }^{7}$
}

\section{RESUMO}

Trata-se de uma revisão sistemática da literatura onde inicialmente buscou-se demostrar as definições de letramento e alfabetização, tendo em vista os diversos aspectos como o antropológico, sociológico, educacional, entre outros, em que estão envolvidos estes fenômenos, para a criança. O objetivo principal foi analisar as publicações originais referentes as práticas pedagógicas para o letramento e alfabetização de crianças no Brasil. Analisou-se os artigos publicados na base de dados Scielo e na plataforma CAPES entre os anos de 2015 e 2020, sobre letramento e alfabetização, adotando alguns critérios de inclusão e exclusão. A busca resultou em cinco artigos de relevância para o contexto e a problemática proposta, que foram explorados e discutidos. A concentração dos estudos ocorreu em 2015 e foram encontrados mais estudos de campo e observacionais, identificou-se também um estudo documental, onde o mesmo apresentava a relevância dos embasamentos legais para assegurar o direito ao letramento e a alfabetização. Por fim constatou-se que tendo em vista acontecimentos da atualidade este tema precisa ser estudado levando em consideração o isolamento social e as tecnologias do ensino remoto.

Palavras-chave: Letramento. Alfabetização. Educação.

Submetido em junho de 2020 e aceito em setembro de 2020.

\footnotetext{
1 elianereis@uol.com.br

2 bj-sb@hotmail.com

${ }^{3}$ mariaedleuza.leu@gmail.com

4 alessandraPorfirio203@gmail.com

5 celsaalbuquerque@ hotmail.com

6 leakarlaeducacaoespecial@gmail.com

7 joselitoaraujo947@gmail.com
} 


\section{INTRODUÇÃO}

A comunicação evoluiu e foi historicamente modificada através a invenção da escrita. Este processo separou a sociedade entre os que conseguiam ou não interpretar os códigos. Aplicar este conhecimento foi fundamental para $\mathrm{o}$ desenvolvimento das civilizações. A nossa sociedade atual está baseada em uma cultura letrada e alfabetizada. Ainda que estatisticamente, um percentual considerável de pessoas estão a margem desta realidade, em 2019, cercar de 11 milhões de brasileiros eram analfabetos, segundo o Instituto Brasileiro de Geografia e Estatística (IBGE).

No cotidiano das pessoas, ser letrado e alfabetizado parecem ser a mesma coisa, porém ler e escrever sempre foram eventos distintos, assim como o letramento e a alfabetização. Semanticamente, letramento é a capacidade de ler e de escrever ou de interpretar o que se escreve. (PRIBERAM, 2020) já a definição de alfabetização é ensino da leitura e o conjunto de conhecimentos adquiridos na escola. (PRIBERAM, 2020)

Desta forma, o letramento está relacionado a aplicação do conhecimento adquirido no processo de alfabetização na vida do sujeito e vai além das experiências do meio escolar, é um fenômeno social para o letrado. É como o sujeito consegue interpretar o que está a sua volta, é como ele se relaciona com os significados das coisas, além do código de escrita formal. Pois, a construção do conhecimento está diretamente relacionada com as experiências vivenciadas pelo indivíduo.

A educação brasileira atualmente está estruturada com base na escolarização. Mas o início do processo de letramento ocorre bem antes da escola formal. A imersão em um ambiente letrado é iniciada desde o nascimento da criança, no convívio com seus familiares ou nos eventos sociais que participa, as práticas de letramento já estão presentes. Quando ocorre o ingresso ao meio escolar, ela já percorreu um vasto percurso o que a torna muitas vezes um sujeito letrado sem ao menos ter iniciado formalmente seu processo de alfabetização. As práticas e os eventos de letramentos vivenciados nas instituições de Educação Infantil dão uma grande contribuição para o desenvolvimento de suas concepções a respeito do que é ler e do que é escrever e para que serve este sistema de escrita. (Espinhosa e Silva, 2015)

Objetivou-se através desta pesquisa analisar as publicações originais referentes as práticas pedagógicas para o letramento e alfabetização de crianças no Brasil. 


\section{METODOLOGIA}

A metodologia adotada no presente trabalho foi a revisão sistemática da literatura por meio de buscas na base de dados SciELO e no Portal de Periódicos da CAPES, utilizando-se os descritores letramento, alfabetização e educação conectados pelo conector booleano "e".

Para o escopo deste estudo, consideraram-se como critérios de inclusão: Estudos publicados entre 2015 e 2020, que respondiam à pergunta norteadora e atendiam a temática estabelecida pelos descritores, em língua portuguesa. Foram excluídos artigos de revisão e os que não estavam disponíveis na integra. Criou-se um fichamento protocolar contemplando: títulos, ano, autor, palavras chave e tipo de pesquisa.

O Quadro abaixo demonstra como os descritores foram utilizados e a quantidade de estudos localizados em cada uma das bases de dados.

Quadro 1- Descritores, bibliotecas e quantidade de trabalhos encontrados na busca.

\begin{tabular}{|l|c|c|c|}
\hline \multicolumn{1}{|c|}{ DESCRITORES } & SCIELO & CAPES & $\begin{array}{c}\text { APÓS CRITÉRIOS DE } \\
\text { INCLUSÃO E } \\
\text { EXCLUSÃO }\end{array}$ \\
\hline $\begin{array}{l}\text { Letramento "e" Alfabetização "e" } \\
\text { Educação }\end{array}$ & 27 & -- & 4 \\
\hline Letramento "e" Alfabetização & -- & 26 & 1 \\
\hline
\end{tabular}

Fonte: Autoria própria.

\section{RESULTADOS E DISCUSSÕES}

A busca resultou em 27 artigos na base de dados SciELO, 26 no Portal de Periódicos da Coordenação de Aperfeiçoamento de Pessoal de Nível Superior (CAPES), totalizando 53 artigos. Desses, 36 foram excluídos pelo título, 9 pelo resumo, 1 era duplicado, 2 pela leitura na integra, sendo selecionados e analisados 5 artigos.

Apresentação dos resultados segundo o Quadro 2- Resultados após os critérios de inclusão e exclusão, demostra que a concentração maior de estudos originais sobre este tema ocorreu em 2015 , percebemos também que diversas abordagens podem ser feitas com relação a este tema pois os eventos de letramento e alfabetização afetam diversos aspectos da vida do sujeito.

Outro ponto observado, os trabalhos de campo foram baseados a partir da observação do cotidiano e de interação com as crianças e professores. De maneira geral, os artigos analisaram como ocorre os 
fenômenos do letramento e da alfabetização.

Ainda estudaram o processo associado a outras abordagens pedagógicas além da tradicional.

Quadro 2. Trabalhos encontrados nas bibliotecas após a aplicação dos critérios definidos na presente pesquisa.

\begin{tabular}{|c|c|c|c|c|c|}
\hline $\mathbf{N}$ & TÍTULO & ANO & AUTORES & PALAVRAS-CHAVE & $\begin{array}{c}\text { TIPO DE } \\
\text { PESQUISA }\end{array}$ \\
\hline 1 & $\begin{array}{c}\text { Alfabetização e } \\
\text { letramento em língua } \\
\text { materna e em matemática }\end{array}$ & 2015 & $\begin{array}{c}\text { Madeline } \\
\text { Gurgel Barreto } \\
\text { Maia; Cristina } \\
\text { Maranhão }\end{array}$ & $\begin{array}{c}\text { Alfabetização e } \\
\text { letramento; Língua } \\
\text { materna; Alfabetização } \\
\text { matemática; Estratégias } \\
\text { de ensino; Ensino } \\
\text { Fundamental }\end{array}$ & $\begin{array}{c}\text { Pesquisa } \\
\text { qualitativa } \\
\text { documental }\end{array}$ \\
\hline 2 & $\begin{array}{l}\text { Alfabetização e } \\
\text { letramento na educação } \\
\text { infantil: analisando } \\
\text { práticas na pré-escola }\end{array}$ & 2015 & $\begin{array}{c}\text { Daniela } \\
\text { Cardoso } \\
\text { Espinosa; } \\
\text { Thaise da Silva }\end{array}$ & $\begin{array}{l}\text { Alfabetização. } \\
\text { Letramento Infantil. } \\
\text { Educação Infantil. }\end{array}$ & $\begin{array}{l}\text { Pesquisa } \\
\text { qualitativa } \\
\text { de campo }\end{array}$ \\
\hline 3 & $\begin{array}{l}\text { A alfabetização e sua } \\
\text { relação com o uso do } \\
\text { computador: O suporte } \\
\text { digital como mais um } \\
\text { instrumento de ensino- } \\
\text { aprendizagem da escrita }\end{array}$ & 2015 & $\begin{array}{l}\text { Julianna Silva } \\
\text { Glória; Isabel } \\
\text { Cristina Alves } \\
\text { da Silva Frade }\end{array}$ & $\begin{array}{l}\text { Letramento digital; } \\
\text { Alfabetização; Cultura } \\
\text { digital; Suportes e } \\
\text { instrumentos de escrita. }\end{array}$ & $\begin{array}{l}\text { Pesquisa } \\
\text { qualitativa } \\
\text { de campo }\end{array}$ \\
\hline 4 & $\begin{array}{l}\text { O letramento e o brincar } \\
\text { em processos de } \\
\text { socialização na educação } \\
\text { infantil brincadeiras } \\
\text { diferentes }\end{array}$ & 2015 & $\begin{array}{c}\text { Vanessa Ferraz } \\
\text { Almeida Neves; } \\
\text { Maria Lúcia } \\
\text { Castanheira; } \\
\text { Maria Cristina } \\
\text { Soares Gouvêa. }\end{array}$ & $\begin{array}{l}\text { Brincar; Letramento; } \\
\text { Educação Infantil; } \\
\text { Etnografia Interacional }\end{array}$ & $\begin{array}{l}\text { Pesquisa } \\
\text { qualitativa } \\
\text { de campo }\end{array}$ \\
\hline 5 & $\begin{array}{c}\text { Práticas de leitura, } \\
\text { gêneros e suportes } \\
\text { textuais do contexto } \\
\text { familiar na perspectiva de } \\
\text { crianças em classe de } \\
\text { alfabetização }\end{array}$ & 2020 & $\begin{array}{c}\text { Luciana } \\
\text { Piccolii; Maria } \\
\text { Isabel Habckost } \\
\text { Dalla Zeni }\end{array}$ & $\begin{array}{l}\text { Práticas de leitura; } \\
\text { Gêneros textuais; } \\
\text { Suportes textuais; } \\
\text { Alfabetização }\end{array}$ & $\begin{array}{l}\text { Pesquisa } \\
\text { qualitativa } \\
\text { de campo }\end{array}$ \\
\hline
\end{tabular}

Fonte: Autoria própria.

Maranhão (2015), fez uma análise documental ampla e mostra que o ensino fundamental no Brasil, em sua trajetória, tem passado por diversas modificações, a partir de políticas públicas que visam proporcionar aos estudantes, uma educação de qualidade. Os três primeiros anos da vida escolar de uma criança, refere-se ao período em que deve ocorrer sua alfabetização escolar.

Nessa perspectiva a escola buscou atender as exigências do novo modelo do 
ciclo de alfabetização para garantir que o ingresso da criança de seis anos de idade no ambiente escolar aconteça de maneira exitosa, cumprindo o que determina o documento, Ensino Fundamental de nove anos: orientações gerais. (BRSIL,2004)

Para desempenhar bem o seu papel de formar cidadãos alfabetizados e letrados, a escola deve considerar importante vários aspectos da vida da criança que inicia seu ciclo de alfabetização, na maioria das vezes sem as etapas anteriores já serem alcançadas. Além desse agravante, deve-se também levar em conta o ambiente doméstico em que estão inseridas, o tempo que necessita para ser alfabetizadas considerando que cada uma delas é um universo diferente.

Ainda de acordo com Maia e Maranhão (2015), no processo de alfabetização e letramento em língua materna, é importante observar em que ambos se baseiam. A alfabetização consiste em um processo mais restrito. E o letramento, é interpretado como um dinamismo de uma abrangência mais relevante, havendo uma interdependência entre um e outro.

O estudo foi bem claro e mostra um panorama documental de como são baseadas as políticas públicas do Brasil, de fácil compreensão, define os processos e as múltiplas faces em que ocorrem os fenômenos do letramento e da alfabetização. No entanto, poderia ter apresentado os mesmos aspectos de uma forma mais sucinta e menos redundante em alguns pontos.

De outra maneira, o trabalho de Espinhosa e Silva (2015) que teve como objetivo principal investigar quais são as práticas e os eventos de letramento vivenciados pelas crianças na Educação Infantil, fazendo a análise de como se concebe a alfabetização e o letramento nesta etapa de ensino, analisando a mesma fenomenologia mas faz uso de um estudo de campo.

Tomando como base o estudo observacional em uma turma de pré-escola I, na faixa etária de 4 e 5 anos. Com o intuito de investigar como acontecem de fato esses eventos de letramento, bem como as crianças interagem diante disso. As autoras declaram que:

"O ensino da leitura e da escrita
deve ser entendido como prática de
um sujeito agindo sobre o mundo
para transformá-lo, afirmando,
desta forma, sua liberdade."

Por se tratar de um estudo focal, de um período observação indefinido, os caminhos metodológicos ficaram pouco evidentes, forma de escrita e o layout dificultaram o entendimento da abordagem utilizada pelas autoras. Observamos também que não há uma definição clara da 
época de observação e do local onde o estudo ocorreu.

Um outro pondo abordado neste mesmo trabalho é que:

“[...]aprender a ler e escrever é um desejo das crianças, uma vez que utilizam cenas de sala de aula em suas brincadeiras. Cabe ao professor tornar a aquisição do sistema de escrita alfabético objeto do interesse infantil, algo que tenham desejo de dominar."

Neves, Castanheira e Gouvêa (2015) também realizaram um trabalho de campo com a intenção de examinar, baseando-se na análise do cotidiano de uma escola pública de educação infantil em Belo Horizonte, MG, os significados do ler, escrever e brincar para crianças na préescola. Conduzindo as discussões sobre o papel do letramento e da alfabetização na educação infantil, visto que, fora estabelecido o ensino fundamental de nove anos.

O foco principal do estudo foi:

"[...] acompanhar o processo de passagem de crianças da escola de educação infantil para a escola de ensino fundamental e conhecer como, na sala de aula, as crianças e professoras utilizaram o tempo e os espaços para definir como, com quem, quando e onde desenvolveriam suas atividades e quais as consequências dessas atividades para o que as crianças poderiam aprender nesses espaços institucionais." (NEVES, CASTANHEIRA e GOUVÊA p.218, 2015).
Através de um estudo de caso de natureza etnográfica sobre como as crianças, oriundas de famílias com índices de vulnerabilidade social elevado, vivenciam a transição de uma escola de educação infantil para uma escola de ensino fundamental em duas instituições da rede municipal de ensino de Belo Horizonte, as autoras apresentam diversos aspectos do processo de letramento e alfabetização, bem como as relações sociais oriundas do ambiente escolar, analisando as relações entre o letramento e o brincar, pontuando como as crianças conseguiram lidar com esses aspectos nesse contexto e compreender os significados do brincar, ler e escrever para esse grupo (NEVES, CASTANHEIRA e GOUVÊA, 2015).

O estudo apresenta-se bem estruturado, como fotos e esquemas que deixam claro como foi o percurso da pesquisa, ressaltando os pontos mais relevantes do período de observação, bem como as transcrições de diversos momentos onde ocorreu a avaliação do que fora vivenciado por parte das crianças (NEVES, CASTANHEIRA e GOUVÊA, 2015)

No decorrer do trabalho foi evidenciado que ao mesmo tempo em que houve uma estruturação das atividades pedagógicas pelas professoras ao longo do ano, as crianças puderam participar de 
maneiras diferenciadas dentro de um conjunto de opções oferecido ao grupo.

Diversos eventos sociais, antropológicos, ocorrem em paralelo a fase em que a criança é iniciada na escola. A coordenação das próprias vontades e desejos com as expectativas e demandas estabelecidas nesse espaço institucional por participantes do grupo foi oportunizada através da socialização das crianças no ambiente dessa escola de educação infantil. Dentro da dinamicidade entre o pessoal e o grupal, as crianças estabeleceram-se como membros dessa turma. O destaque é para duas das práticas sociais estabelecidas pela turma, a roda de conversa e o brincar, estão presentes no discurso do campo da educação infantil, tanto em documentos oficiais quanto nas formações de professores propostas pela Secretaria Municipal de Educação de Belo Horizonte. (NEVES, CASTANHEIRA e GOUVÊA, 2015).

O que também é destaque na análise de Maia e Maranhão (2015) são essas prerrogativas oficiais já bem estabelecidas, o que torna notável a articulação entre as práticas educativas das professoras e o campo discursivo da educação, presentes no trabalho de Neves, Castanheira e Gouvêa, vale ressaltar que as atividades propostas não são apenas escolhas pessoais, mas, praticas fundamentadas.
Contextualizar o que se vive em sala de aula e apresentar um olhar mais tecnológico com relação ao letramento e a informática, tendo em vista que os pequenos têm acesso as tecnologias cada vez mais cedo. Foi o objetivo do trabalho de Glória e Frade (2015).

Metodologicamente este mesmo trabalho foi estruturado por meio da pesquisa qualitativa, com uma proposta de intervenção colaborativa, com a proposição de acompanhar crianças de 6 anos em laboratório de informática de escola pública em Belo Horizonte, Minas Gerais, durante o ano de 2009, em várias situações de atividades de escritura e leitura na tela do computador. A localidade é um ponto de congruência entre a pesquisa de Glória e Frade (2015) e a de Neves, Castanheira e Gouvêa.

O trabalho de Glória e Frade (2015) utilizou-se dos procedimentos de observação, anotação, filmagem e entrevistas. Observa-se que manter um procedimento ético em relação aos sujeitos participantes da pesquisa, com relação aos registros, os nomes de nossos colaboradores foram codificados.

Diversos aspectos da aprendizagem da escrita foram observados neste trabalho. As entrevistas das crianças tornam o texto leve e prazeroso de ler. Um ponto que merece destaque é que à característica 
multimodal dos textos que aparecem nos programas de escrita no computador, isto é, são variados os modos pelos quais o texto pode se apresentar ao sujeito no monitor. Pois, escrever no caderno é distinto de escrevê-lo na tela, uma vez que, neste último caso, a criança fica diante de um teclado com diversos caracteres e signos diferenciados.

Apesar do período de observação da pesquisa de de Glória e Frade (2015) ter ocorrido em 2009, ainda é um tema bastante atual que merecia mais estudos exploratório. A limitação da literatura sobre esta perspectiva mais tecnológica, torna o tema do trabalho pouco discutido. Geralmente, é observado várias divergências entre o sistema público e o sistema privado, desde o tipo dos materiais didáticos as práticas pedagógicas. Entretanto, os estudos apontam que diversas iniciativas criativas para o letramento e alfabetização também surgem na educação pública.

No estudo de Piccolii e Zeni (2020) analisou-se as práticas de leitura vinculadas ao contexto familiar de crianças de segundo ano do Ensino Fundamental de escola municipal de Porto Alegre/RS, bem como textos e materiais utilizados por elas em tais práticas. Abrangendo os campos do letramento, alfabetização e leitura, vistos sob os prismas social, cultural, linguístico e pedagógico.

Ainda se tornou notório, à partir dos estudos de Piccolii e Zeni (2020), que as crianças oriundas das família de menor poder aquisitivo, têm acesso a variedade de materiais de leitura e os reconhecem em seus suportes, bem como, em vários contextos, assumem o papel principal das práticas de leitura.

As autoras concluem que:

[...] é urgente, pois, investir no
trabalho com os gêneros a partir de
sequências didáticas, adequadamente
planejadas, que possibilitem a
apropriação, desde o início da
alfabetização, das características
estruturais e sociodiscursivas já
mencionadas.

O estudo buscou demonstrar a potencialidade e a necessidade de um olhar mais abrangente e multifacetado para o entendimento das práticas de leitura das crianças, afim de que as inter-relações com as práticas escolares sejam mais aproximadas. Partindo do pressuposto que foi visibilizar os conhecimentos das crianças acerca da leitura, na tentativa de promover a ampliação e a complexificação desse repertório na escola tendo em vista a formação de leitores proficientes e que estram inserido no contexto familiar e comunitário (PICCOLII e ZENI, 2020)

A distribuição dos estudos acerca deste tema por regiões no Brasil apresenta 
uma concentração maior no sudeste e no sul, notou-se a ausência de estudos mais atualizados, bem como situados norte, nordeste e cetro-oeste. Outro ponto que vale ressaltar é que o discurso educacional é condizente com as práticas pedagógicas em todos os estudos desta amostra.

Os estudos também apontam que, o tema foi amplamente discutido nos cenários da educação na década de 90, mas atualmente há poucos estudos relacionados, que abordem as experiências de acordo com o avanço das Tecnologias da informação e do Conhecimento (TIC).

\section{CONCLUSÃO}

O desejo de apender a ler e escrever faz parte do processo social em que a criança está inserida. É fundamental que o professor desenvolva o papel de elo entre a experiência escolar e o cotidiano social e familiar dos seus alunos.

A aplicação dos conhecimentos, o gerenciamento de conflitos e emoções está diretamente relacionado com o fenômeno do letramento. Mas apesar de ser menos abrangente a alfabetização é fundamental ao desenvolvimento da leitura e da escrita, dando a base para outros conhecimentos nas series mais avançadas.
Ainda é possível salientar que, neste trabalho o enfoque foi a vertente educacional no fenômeno do letramento, correlacionando as práticas pedagógicas e a vivencia dos alunos da educação infantil. Porém, compreendemos que o sujeito é plural e suas experiências com a leitura e a escrita perpassam diversas áreas de sua vida. Tornando-se alicerce para as experiências futuras, possibilitando diversas descobertas para os letrados, na vida cotidiana e escolar.

Diante de tudo que foi apresentado neste estudo, a mudança do cenário atual, da escola pra casa, da educação presencial para a educação remota, notou-se que ainda não há estudos que levem em consideração o cenário atual, com relação ao ensino remoto nas séries iniciais por conta da pandemia da corona vírus.

É preciso que as políticas públicas sejam efetivadas com comprometimento em todas as esferas educacionais. A solidez na base proporciona uma melhor estrutura para o sistema como um todo, e a base é a educação infantil, particularmente, nas series de letramento e alfabetização 


\section{REFERÊNCIAS}

"Alfabetização", In: Dicionário Priberam da Língua Portuguesa [em linha], 20082020. Disponível em: <https://dicionario.priberam.org/alfabetiza \%C3\%A7\%C3\%A3o> Acesso em: 04 de Set. 2020.

BRASIL. Ministério da Educação. Ensino fundamental de 9 anos: orientações gerais. 2. ed. Brasília: SEF, 2004

ESPINOSA, D.C.; SILVA, T. Alfabetização e letramento na educação Infantil: analisando práticas na pré-escola.

Revista de Educação, Dourados, MS, v.3, n5, 2015. Disponível em:

<https://doaj.org/article/a74e4996c52c42ff a2306587dfe65d2d> Acesso em: 04 de set. 2020

GLÓRIA, J.S.; FRADE, I.C.A.S. A alfabetização e sua relação com o uso do computador: o suporte digital como mais um instrumento de ensino-aprendizagem da escrita. Educação em Revista, Belo Horizonte, v.31, n.03, p. 339-358, 2015 Disponível em:

<https://www.scielo.br/scielo.php?script=s ci_arttext\&pid=S0102-

46982015000300339\&lang=pt $>$ Acesso em: 04 em set. 2020

\section{INSTITUTO BRASILEIRO DE} GEOGRAFIA E ESTATÍSTICA - IBGE Pesquisa Nacional por Amostra de Domicílios Contínua - PNAD Contínua2018. Disponível em:

<https://www.ibge.gov.br/estatisticas/socia is/populacao/9171-pesquisa-nacional-poramostra-de-domicilios-continuamensal.html $?=\& \mathrm{t}=$ downloads $>$
Acesso em: 04 de set.2020

"Letramento", In Dicionário Priberam da Língua Portuguesa [em linha], 2008-2020, c $<$ https://dicionario.priberam.org/letrament o> Acesso em 04 de set. 2020.

MAIA, M. G. B.; MARANHÃO, C. Alfabetização e letramento em língua materna e em matemática. Ciências de Educação, Bauru, v. 21, n. 4, p. 931-943, 2015.

Disponível em:

$<$ https://www.scielo.br/scielo.php?script=s ci_arttext\&pid=S1516-

$73132015000400009 \&$ lang=pt $>$ Acesso em: 04 de set. 2020

NEVES, V.F.A.; CASTANHEIRA. M.L.; GOUVÊA, M.C.S. O letramento e o brincar em processos de socialização na educação infantil. Revista Brasileira de Educação, v. 20, n. 60, 2015. Disponível em:

$<$ https://www.scielo.br/scielo.php?script=s ci_arttext\&pid=S1413-

24782015000100215\&lang=pt $>$ Acesso em: 04 de set. 2020

PICCOLI, L.; ZEN, M.I.H.D. Práticas de leitura, gêneros e suportes textuais do contexto familiar na perspectiva decrianças em classe de alfabetização. Educação em

\section{Revista, Dossiê Alfabetização e} Letramento no Campo Educacional, v.36, 2020. Disponível em: $<$ https://www.scielo.br/scielo.php?script=s ci_arttext\&pid=S0102$46982020000100706 \&$ lang $=p t>$. Acesso em: 04 de set. 2020 